DOI: $\underline{\text { https://doi.org/10.24867/01FA04Cucovic }}$

\title{
ARHITEKTONSKO-URBANISTIČKA STRATEGIJA OPŠTINE SJENICA, PROMOVISA- NJE IDENTITETA U CILJU PODIZANJA VREDNOSTI TURISTIČKIH POTENCIJALA
}

\section{ARCHITECTURAL AND URBAN STRATEGY OF SJENICA MUCIPILITY, PROMO- TING IDENTITY IN ORDER TO INCREASE THE TOURIST POTENTIALS VALUE}

\author{
Azra Ćućović, Darko Reba, Fakultet tehničkih nauka, Novi Sad
}

\section{Oblast- ARHITEKTURA I URBANIZAM}

Kratak sadržaj - Srbija je zemlja koja ima kvalitetnu $i$ raznovrsnu osnovu za razvoj turizma. Ona raspolaže velikim prirodnim atraktivnostima, što upućuje na to da se u Srbiji mogu razvijati brojni vidovi turizma, naročito ako se uzme u obzir prostorna raznovrsnost prirodnih potencijala. Karakteristike prostora, posebno geografskosaobaćajnog položaja, hidrografije, biljnog $i$ životinjskog sveta, klime $i$ ostalih prirodnih obeležja u Srbiji, mogu predstavljati dobru osnovu za razvoj turističke privrede, odnosno za uključivanje Srbije u najvažnije međunarodne turističke tokove $i$ pravce. Planinski reljef je značajan potencijal kojim Srbija raspolaže, $i$ ima poseban značaj $u$ strukturi privrednih delatnosti. Srbija ponovo postaje primarna turistička destinacija. Prema statistici Svetske turistčke organizacije (WTO), Srbija je bila jedina zemlja u Evropi koja je tokom prih pet meseci 2009.godine zabeležila porast posete iz inostranstva (4\%).

Klučne reči: Turizam, priroda, atraktivnosti

Abstract - Serbia is a country that has a good and diverse basis for the development of tourism. It has great natural attractions, suggesting that many forms of tourism can be developed in Serbia, especially considering the spatial diversity of natural potentials. The characteristics of the area, especially the geographical distribution, hydrography, plant and animal world, climate and other natural features in Serbia, can represent a good basis for the development of the tourist economy, that is, for inclusion of Serbia into the most important international tourist flows and directions. Mountain relief is a significant potential that Serbia has at its disposal, and has a special importance in the structure of economic activities. Serbia is again becoming the primary tourist destination. According to the World Tourism Organization(WTO) statistics, Serbia was the only country in Europe that recorded an increase in foreign visits 4\% over the first five months of 2009.

Keywords: Tourism, nature, attraction

\section{UVOD}

Tema master rada odnosi se na istraživanje i promovisanje identiteta opštine Sjenica u cilju podizanja vrednosti turističkih potencijala koji predstavljaju osnovu za razvoj turizma na ovom prostoru. Strategijom ovog rostora biće predstavljeni turistički potencijali opštine Sjenica, tačnije

\section{NAPOMENA:}

Ovaj rad proistekao je iz master rada čiji je mentor bio prof. dr Darko Reba. prirodne, geografske, kulturne i prostorne karakteristike i specifičnosti koje se mogu iskoristiti u cilju razvoja turizma za buduće prostorne intervencije, ukazivanjem na nedostatke koji bi se trebali sanirati kao i predlog strategije za njen dalji razvoj i stvaranje jasnog identiteta kao budućeg razvijenog mesta. Neophodno je analizirati turističe potencijale i pronaći odgovarajuće modele lako bi se potencijali valorizovali na najbolji način, čiji bi krajnji cilj bio turistički razvoj opštine Sjenica i time dao doprinos trajnom pozicioniranju na turističkoj mapi Evrope.

\section{ANALIZA POSTOJEĆEG STANjA OPŠTINE SJENICA}

Opština Sjenica se nalazi na Pešterskoj visoravni $u$ jugozapadnom delu Srbije. Po svojoj površini od 1059km kvadratnih, Sjenica spada u jednu od najvećih opština $u$ Srbiji. Sjenica predstavlja centar Pešterske visoravni sa svega 16.000stanovnika. Sjenica se prvi put pominje u povelji koju je kralj Uroš dao Dubrovčanima 12.avgusta 1253.godine, kao mesto gde su Dubrovčani plaćali carinu [1]. Sjenica je u Evropi poznata kao veoma hladan kraj, pa se u zimskim danima često ubraja u najhladnija mesta Evrope. Godine 2005. je izmerena najniža temperature od -42 stepena C. U odnosu na sve ostale gradove u Srbiji, Sjenica je jedan od najhladnijih gradova.

\subsection{Pešterska visoravan}

Najveća visoravan na Balkanskom poluostrvu i jedna od najvećih u Evropi, poslednjih godina je postal pravi hit među ljubiteljima turizma, novih neistraženih predela $\mathrm{i}$ netaknutih, ničim narušenih prirodnih lepota. Sa nadmorskom visinom od 1500 metara i površinom od 63 kvadratna kilometra ona predstavlja jedinstvenu, očaravajuću, ni sa čim uporedivu prirodnu oazu u srcu Evrope [2].

Uvac- kao najveća pritoka Lima izvire na području opštine Sjenica. Uvac ima jedan od najlepših kanjona $u$ Evropi, sa čuvenim meandrima Uvca, čija visina ponekad iznosi i do 100 metara. Najlepši deo Uvačkih meandara nalazi se na području opštine Sjenica, pa ovdašnji ljudi ponekad kažu : "Ono što je za Ameriku kanjon Kolorado, to je za Sjenicu kanjon Uvca".

Sjeničko jezero- Dugo je 25 kilometara, sa maksimalnom dubinom od 108 metara i branom koja je duga 160 i visoka 110 metara. Sjeničko jezero je ispunilo duboku klisuru koju je Uvac usekao u krečnjački masiv pešterske visoravni. Na obalama ovog jezera nalazi se Specijalni rezervat prirode Uvac i najveća kolonija Beloglavog supa na Balkanu. 


\subsection{Zaključak analize postojećeg stanja}

Glavni cilj bio je ispitati funkcionalne i prostorne potencijale kako užeg, tako i šireg područja opštine Sjenica, i na osnovu postojećih namena i sadržaja obogatiti ponudu centra grada kao i šireg gradskog jezgra.

$\mathrm{Na}$ osnovu detaljne analize postojećeg stanja i definisanja potencijala turističke privrede na ovom prostoru koji su minimalno iskorišteni (pojedini gotovo uopšte), ulaganja minimalna, iako opština Sjenica poseduje veliki broj potencijala za razvoj turističke privrede, stvorena je slika o gradu i primarnim potencijalnim intervencijama koje bi unapredile i ubrzale njegov razvoj. Očuvana priroda, zdrava okolina, bogatstvo prirodnog nasleđa, velika nadmorska visina, čist vazduh i okolina, kulturno istorijsko nasleđe, sve to čini poseban motiv za razvoj turizma, i stvaranju novih jedinstvenih ponuda za posetioce.

\section{TURIZAM}

Turizam predstavlja delatnost sastavljenu i zavisnu od niza raznovrsnih faktora međusobno usklađenih. Turizam je u suštini veoma složena i mnogofukncionalna društveno-ekonomska kategorija koja proizilazi iz niza veoma složenih bioloških, socioloških, demografskih, ekonomskih, prirodnih, prostornih, arhitektonskih i drugih relevantnih činjenica i pojava.

Turizam bira atraktivna, karakteristična, najkvalitetnija, najvrednija, najlepša prirodna bogatstva uz reke, jezera, na planinama, i u nizinama, kao i uz banjske lečilišne centre, a sa svim ovim prirodnim resursima Srbija je izuzetno bogata. Definisanjem pojmova turista i turizma nije jednostavno. Ono što je evidentno jeste da je turizam dinamičan fenomen koji se stalno menja. Veoma je teško precizno odrediti i definisati pojmove turista i turizam, sa obzirom na to da oni imaju različito značenje u različitim kulturama, a da univerzalna definicija još uvek nije prihvaćena [3].

Turizam, kao jedna od vodećih grana privrede današnjice svakim danom se sve više razvija i širi. Na teritoriji opštine Sjenica analizom prirodnog i kulturnog bogatstva prepoznati su potencijali za razvoj planinskog turizma i seoskog- etno turizma.

Osim hrane, ekološki i prirodni ambijent doprinosi povećanju stranih turista, na osnovu čega se može uvideti potencijal opštine Sjenica i Pešterske visoravni, koji turstima pruža veliki broj različitih ambijentalnih celina $\mathrm{u}$ prirodi, a isto tako autentične proizvode iz domaće kuhinje.Međutim, ništa od ovoga se ne može ostvariti bez značajnih intervencija u prostoru, koje je neophodno izvesti, a to su pre svega unapređenje ponude u turizmu i ugostiteljstvu, kao i poboljšanje infrastructure, trgovine i menadžmenta.

\section{SPORT I REKREACIJA}

Pešterska visoravan sa svojom klimom i nadmorskom visinom idealno je mesto za rekreaciju, sport i popravljanje fizičke forme. Brojne sportske ekipe iz naše zemlje i inostranstva koristile su klimatske pogodnosti ove visoravni za letnje i zimske pripreme sportista $u$ mnogim disciplinama. Ovde su se pripremale brojne domaće i inostrane reprezentacije, prvoligaški fudbalski i košarkaški klubovi. Pešterska visoravan, sa okolnim visokim planinama, je posebno pogodna za zimske sportove. Visoravan okružena planinama predstavlja idealno mesto iz koga se može pešačiti od svih planinskih vrhova. Brojna planinska društva iz cele naše zemlje poslednjih godina redovno posećuju ovaj kraj, spajajući obilazak jezera u kanjonu Uvca sa vrhovima Golije, Zlatara, Javora ili Jadovnika. Pešačke staze u ovim krajevima su brojne, pogledi sa planinskih vrhova nezaboravni, utisci nesvakidašnji i začuđujući.

\section{PREDLOZI REŠENjA U CILjU OSTVARENjA STRATEGIJA}

Vodeći se analizom postojećeg stanja kao i nedostacima koji su zaključeni na osnovu analize, biće predloženo par intervencija na teritoriji opštine Sjenica. Cilj je bio prepoznati sve prirodne potencijale na ovom prostoru koji su trenutno minimalno iskrišteni, a koji kao takvi imaju veliki potencijal za razvoj turističke privrede I vrednovanja mnogih turističkih potencijala uz minimalna ulaganja.

$\mathrm{Na}$ osnovu celokupne analize odlučeno je razviti identitet opštine, povećati njene smeštajne kapacitete, unaprediti pešačke I biciklističke staze u šumskim predelima kako bi se turisti osećali ugodno shodno prirodnom okruženju, razviti različite vrste turizma pre svega planinski i seoski, i aktivirati priobalne zone. Turističkim prihodima Sjenica bi ostvarila značajne finansijske resurse, koji bi svakako uticali na njen dalji razvoj.

\subsection{Predlozi rešenja novih platformi kao potencijalna mesta za vidikovce}

Sa obzirom na to da na Rezervatu Uvca postoji dosta reprezentativnih tačaka sa velikom visinom i sa izuzetnim pogledom na meandre Uvca, koje kao takve sve više privlače posetioce i predstavljaju užitak i odmor za oko posmatrača, odlučila sam da iskoristim par lokacija za projektovanje novih platformi kao izuzetna mesta za nove vidikovce. Ove platforme predstavljaće centralno turističko mesto rezervata. Izgrađene su od drveta, sa potpornim stubovima koji nose platformu. Akcenat sam dala na uređenju pešačkih i biciklističkih staza kretanjem kroz šumu, koje bi kao takve bile pristupačne za posetioce da stignu do određenih primarnih tačaka u okviru rezervata. Ove staze doprinose ugodnom kretanju kroz šumu, raznovrstan biljni svet karakteriše ovaj prostor I oživljava ga kako vizuelno tako i mirisom.

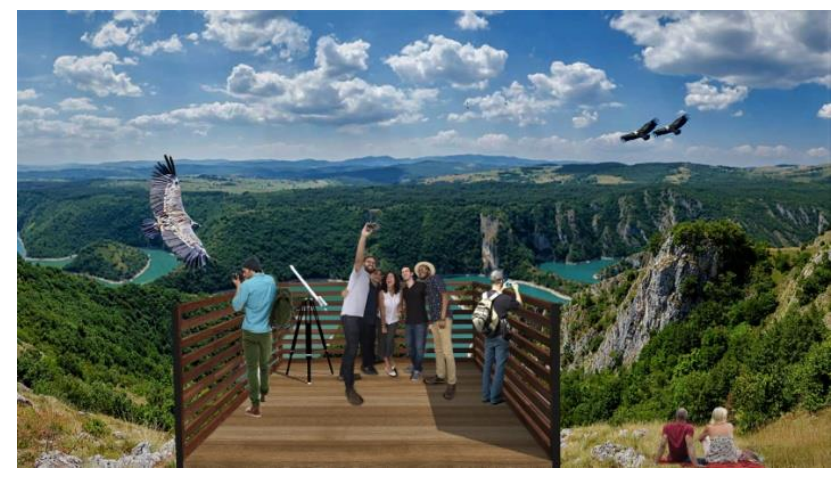

Slika 1: Novoprojektovani vidikovac br.1 


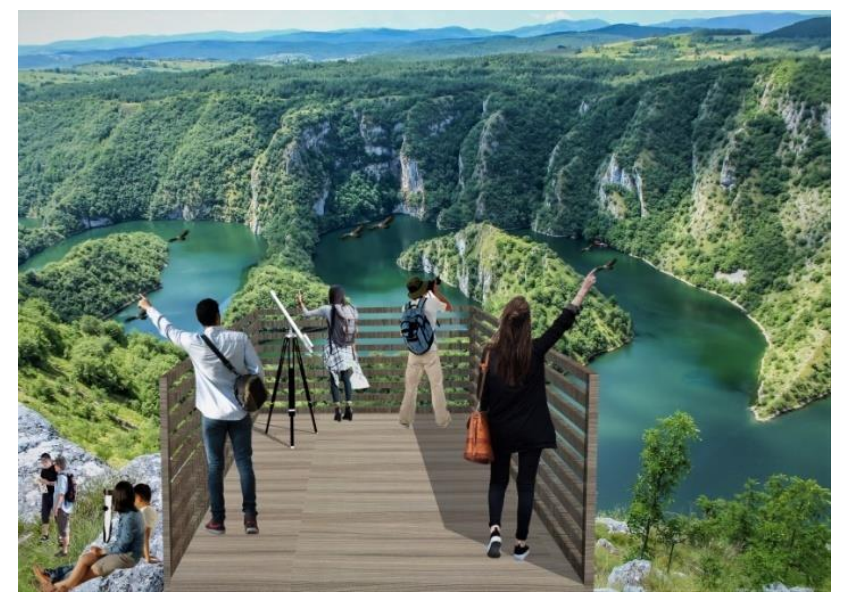

Slika 2: Novoprojektovani vidikovac br.2

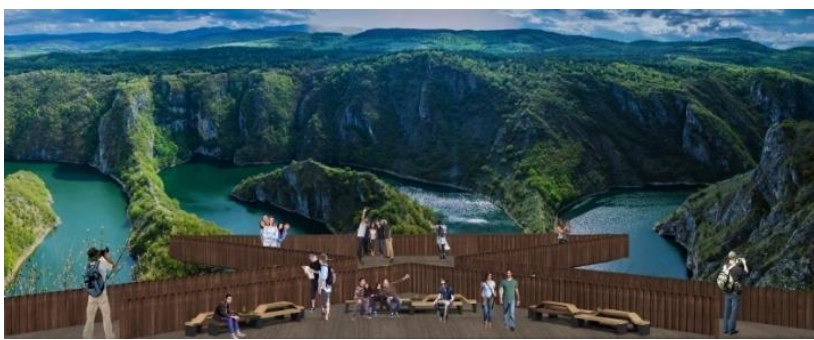

Slika 3: Novoprojektovani vidikovac br.3

\subsection{Smeštajni kapaciteti a vodi}

Projektovani su u delu kamp naselja na Sjeničkom jezeru, i planirani su kao montažne kuće od drvene konstrucije zamišljene kao mali splavovi na vodenoj površini.

Ono što ih čini specifičnim jeste što se boravkom u njima stvara potpuni osećaj jedistva čoveka sa prirodom, rekom i jedinstvenim zelenim okruženjem.

\subsection{Predlog rešenja vikend naselja za turiste}

Sjenica nudi mnoge pogodnosti za rekreaciju i sport, pa shodno tome mnoge sportske ekipe iz naše zemlje i inostranstva koriste ove klimatske pogodnosti za letnje i zimske pripreme sportista u mnogim disciplinama.

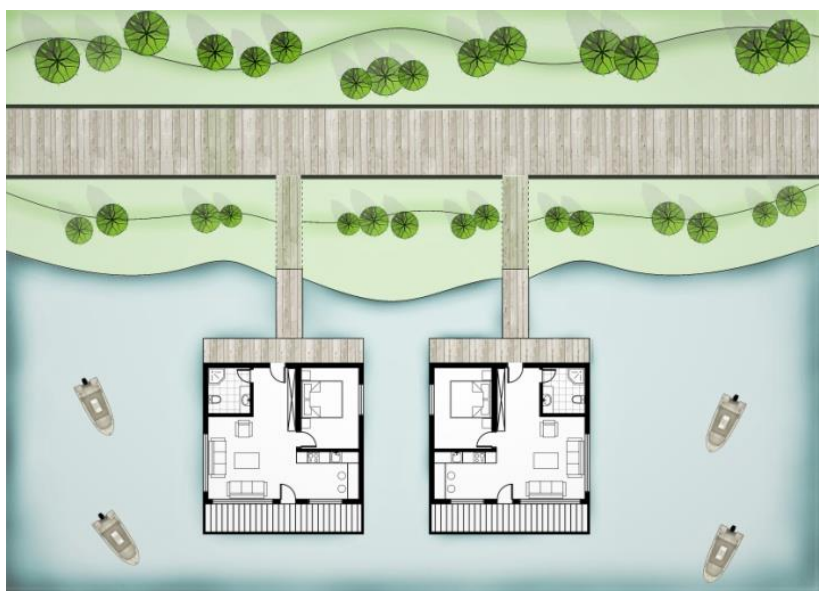

Slika 4: Parterno rešenje smeštajnih kapaciteta na vodi

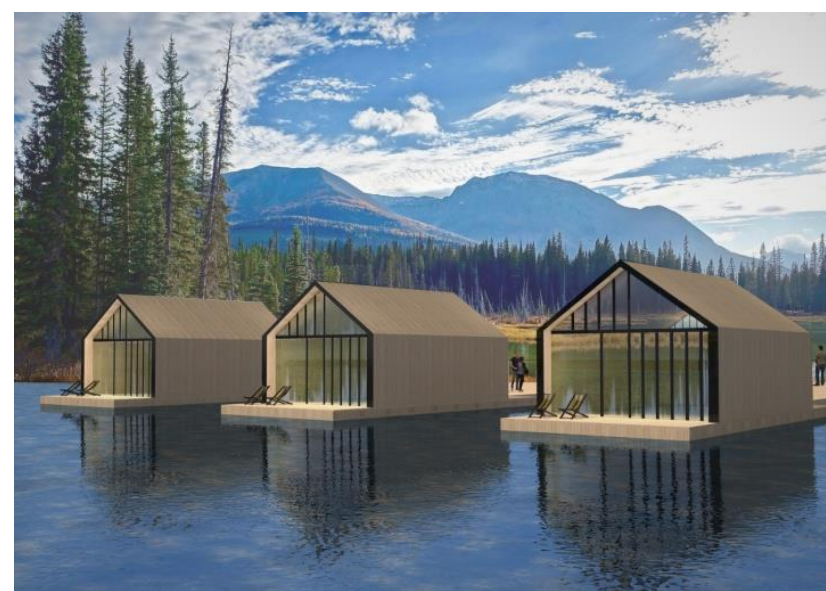

Slika 5: Vizuelni prikaz smeštajnih kapaciteta na vodi

Sa obzirom na to, odlučila sam da takav potencijal iskoristim za razvoj jednog turističkog vikend naselja koje bi bilo namenjeno za boravak sportista. Kuće u okviru ovog vikend naselja osmišljene su kao individualne kuće koje su projektovane po uzoru na tradicionalnu Sjeničku kuću. Ovo vikend naselje nalazi se u blizini Sjeničkog jezera, u predivnom i mirnom okruženju.

Kuće su organizovane tako da se u prizemlju nalaze prostorije za svakodnevne potrebe, dok se na spratu nalazi noćna zona gde sportisti mogu mirno da odmaraju nakon obavljenih treninga. Glavni deo kuće predstavlja staklena bašta koja unosi prirodu u kuću I daje joj nesvakidašnji izgled.

U okviru naselja planirano je i mesto za okupljanje sportista zamišljeno kao manja parkovska celina sa ambijentalnim vrednostima.

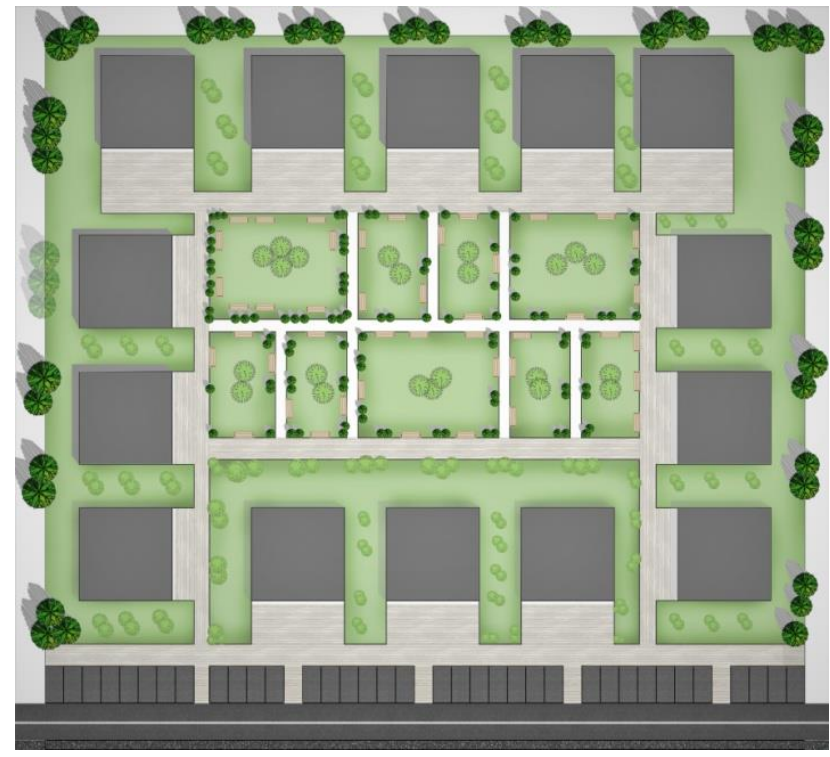

Slika 6: Urbanističko rě̌enje vikend naselja za sportiste 


\subsection{Predlog projekta idejnog rešenja hotela u centralno delu opštine Sjenica}

U centralnom delu opštine Sjenica trenutno ne postoje smeštajni kapaciteti, prvi najbliži hotel udaljen je od centra grada $1,5 \mathrm{~km}$. Lokacija na kojoj se planira hotelsko-gradski kompleks nalazi se u samom centru grada, graniči se sa pešačkom zonom, rekom Grabovicom, i sa jednom od najprometnijih gradskih sabraćajnica ulicom Save Kovačevića. Elementi urbane strukture: gradsko šetalište, most, gradska spomen česma itd. čine ovaj prostor prepoznatljivim.

Objekat je zamišljen tako da je prostorno i oblikovno atraktivan $\mathrm{u}$ okviru sistema vrednosti savremene arhitekture. Pogodna lokacija stvara uslove da se rešenjem mogu iskoristiti prednosti mesta (centra grada) i na taj način formirati i istaći sliku novog ambijenta. Ovaj projekat uključuje sadržaje ugostiteljstva i rekreacije.

Planirani sadržaj treba da postane značajan generator aktivnosti lokalnih korisnika i gostiju iz regiona, i na taj način podigne atraktivnosti šireg prostora u kome se nalazi.

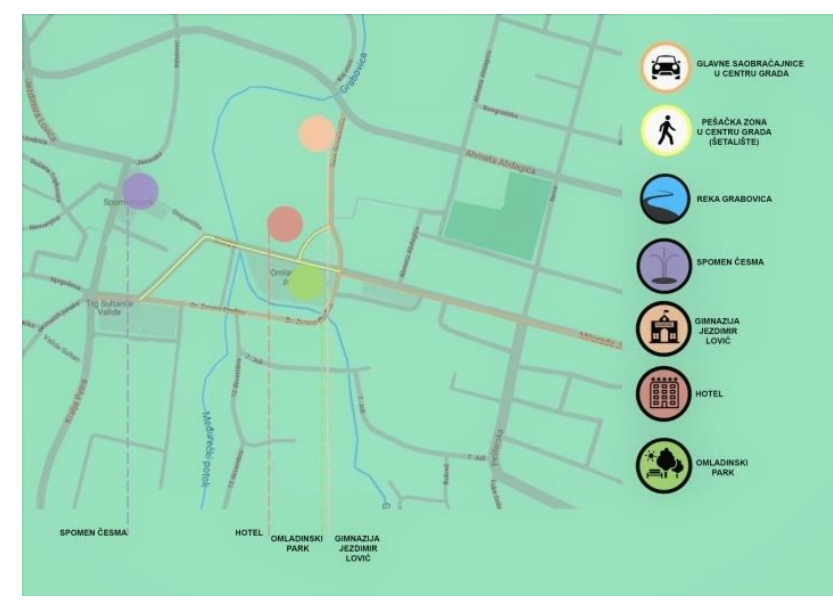

Slika 7: Povezanost centra grada sa novoprojektovanim hotelom

\section{ZAKLJUČAK}

Pošto su turističke atraktivnosti jedan od osnovnih razloga posećivanja Sjenice, a turizam kao grana privredne delatnosti je na veoma niskom stepenu razvijenosti, određene su strategije razvoja turističkih potencijala ove opštine. $\mathrm{Na}$ osnovu postojećih namena i sadržaja data su potencijalna rešenja za razvoj užeg i šireg gradskog jezgra.

Predložene strategije podrazumevaju projektovanje novih platformi na rezervatu Uvca, koji predstavljaju reprezentativna mesta za razvoj novih vidikovaca i planirane su na mestima sa izuzetnim pogledom na meander Uvca, koje će kao takve biti dostupne za sve posetioce rezervata.

Kako bi bezbedno stigli do ovih platformi dati su predlozi uređenja novih pešačkih i biciklističkih staza kroz šumske predele gde se posetiocima nude delovi za odmor i uživanje, a svemu tome veliki doprinos daje bogat biljni svet.
Stateški su određeni i smeštajni kapaciteti na vodenoj površni koji su planirani u kamp zoni Sjeničkoj jezera u vidu montažnih kuća koje su zamišljene kao mali splavovi koji čine vezu između čoveka i prirode. Osim podizanja stepena razvijenosti turizma, strategija obuhvata i predloge razvoja vikend naselja za sportiste koji svake godine koriste klimatske pogodnosti za letnje i zimske pripreme sportskih igara na ovim prostorima.

Ovo naselje zamišljeno je kao samoodrživo, nezavisno od drugih naselja i nalazi se malo izvan centra grada, na prostorima gde sportisti obavljaju svoje pripreme. Strategija uključuje i oživljavanje centralnog dela grada turističkom ponudom predlogom hotelsko-gradskog kompleksa koji je planiran u centralnom delu grada na jednoj od najprometnijih saobraćajnica i glavnom pešačkom zonom.

Ovakva pogodna lokacija stvara uslove da se rešenjem mogu iskoristiti prednosti mesta i još više oživeti centralno područje i stvoriti kvalitetan i prepoznatljiv prostor. Zelene površine izražavaju neposredne ambijentalne vrednosti u okviru kompleksa. Zdrava okolina, velika nadmorska visina, očuvana priroda, bogat biljni i životinski svet, čist vazduh sve su to činioci koji pružaju mogućnosti za razvoj svih ovih turističkih potencijala na ovom prostoru i koji se uz minimalna ulaganja mogu ostvariti za definisaje jasnog identiteta kao jednog od budućeg razvijenog turističkog mesta.

\section{LITERATURA}

[1] Ž.Stepanović, Sjenica i okolina, Sjenica 1975,4.

[2] Turistička organizacija Sjenica

[3] Savremene tendencije u turizmu, hotelijerstvu i gastronomiji 2005.Teorijska dekonstrkcija definicije turizma, Dr.Đorđe Čomić

\section{Kratka biografija:}

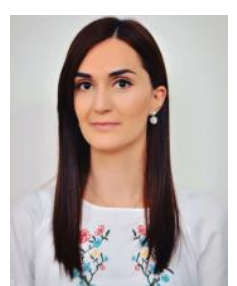

Azra Ćućović, rođena je u Sjenici,1994. godine. Osnovne akademske studije završila je na Državnom univerzitetu u Novom Pazaru, 2017. god.

Master akademske studije odbranila na Fakultetu tehničkih nauka u Novom Sadu 2018.godine.

Kontakt: azra.cucovic@hotmail.com

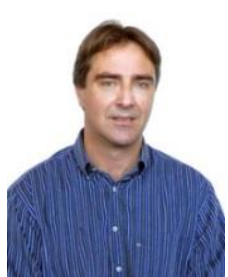

Prof. dr Darko Reba (1968) je vanredni profesor na Departmanu za arhitekturu i urbanizam na Fakultetu tehničkih nauka u Novom Sadu. Diplomirao je 1995.na Arhitektonskom fakultetu u Beogradu, a magistrira 2001. I doktorirao 2005. Na Fakultetu tehničkih nauka u ovom Sadu.

Kontakt:rebad@uns.ac.rs 